\title{
EDITORIAL
}

\section{Special issue: NMME}

\author{
Heather Archambault ${ }^{1} \cdot$ Jin Huang ${ }^{2} \cdot$ Ben Kirtman $^{3} \cdot$ Annarita Mariotti $^{2} \cdot$ Gabriele Villarini $^{4}$
}

Published online: 4 November 2019

(c) Springer-Verlag GmbH Germany, part of Springer Nature 2019

The North American Multi-Model Ensemble (NMME) is a coordinated effort to improve operational seasonal predictions based on the leading North American climate models that is supported by multi-government agencies in the US and Canada. The NMME project represents a significant scientific infrastructure that supports community predictability research, forecast application modeling and operational prediction. This special issue of Climate Dynamics includes 22 papers and reports on many aspects of this research and development emphasizing the importance of the NMME project in enabling a wide variety of prediction and predictability research. Crucially, the peer reviewed papers presented here by the broad science and application communities identify some surprising successes, but also highlight areas where our models and prediction systems need focused efforts in terms of improving forecast quality.

The underlying motivation for the NMME project is the recognition that a multi-model ensemble is an effective and pragmatic approach to quantifying forecast uncertainty. Peer reviewed research included in this collection is providing new compelling evidence that the NMME forecasts are helping to improve seasonal outlooks that are issued to the public by National Oceanic and Atmospheric Administration (NOAA) as well as broader applications.

Importantly, the NMME project seeks to bridge the gap between operational prediction and basic predictability research by providing a platform and infrastructure (i.e., real-time and retrospective forecast data) that enables the rapid transition of research to operations and allows the operational experience to inform research. Indeed, because the project makes the forecast data available in real-time, confronting predictability research questions emerging as part of the real-time activity has become a significant component of the project as reflected in this special issue.

In addition to bridging the gap between prediction and predictability research, a primary focus of the NMME project is to improve the design of multi-model prediction systems, to explore optimal ways to combine models, to establish metrics for verification, to identify sources of complementary skill, and to diagnose mechanisms of conditional skill. The easy availability of retrospective forecast data and the release of real-time model prediction data also enable the development and implementation of a whole spectrum of application models that support real-time decision making.

This Climate Dynamics special issue provides the opportunity for key NMME aspects examined by the broad research, operations and applications communities to be openly documented, as the basis for future progress.

Publisher's Note Springer Nature remains neutral with regard to jurisdictional claims in published maps and institutional affiliations.

Ben Kirtman

bkirtman@rsmas.miami.edu

1 NOAA Geophysical Fluid Dynamics Laboratory, Princeton, NJ, USA

2 NOAA Climate Program Office, Silver Spring, MD, USA

3 University of Miami, Miami, FL, USA

4 University of Iowa, Iowa City, IA, USA 